Portland State University

PDXScholar

Civil and Environmental Engineering Faculty

Publications and Presentations

Civil and Environmental Engineering

$1-2017$

\title{
Mapping the Nonstationary Internal Tide with Satellite Altimetry
}

\author{
Edward Zaron \\ Portland State University, ezaron@pdx.edu
}

Follow this and additional works at: https://pdxscholar.library.pdx.edu/cengin_fac

Part of the Geophysics and Seismology Commons, and the Oceanography Commons

Let us know how access to this document benefits you.

\section{Citation Details}

Zaron, E. D. (2017), Mapping the nonstationary internal tide with satellite altimetry, J. Geophys. Res.

Oceans, 122, 539-554, doi:10.1002/2016JC012487.

This Article is brought to you for free and open access. It has been accepted for inclusion in Civil and Environmental Engineering Faculty Publications and Presentations by an authorized administrator of PDXScholar. Please contact us if we can make this document more accessible: pdxscholar@pdx.edu. 


\section{Journal of Geophysical Research: Oceans}

\section{RESEARCH ARTICLE}

10.1002/2016JC012487

Key Points:

- New maps illustrate the geography of the nonstationary $\mathrm{M}_{2}$ internal tide.

- Nonstationary internal tides are a significant source of ageostrophic sea level variability for the SWOT mission.

- Locations with the largest stationary and nonstationary tides are highlighted.

\section{Correspondence to:}

Edward D. Zaron,

ezaron@pdx.edu

Citation:

Zaron, E. D. (2017), Mapping the nonstationary internal tide with satellite altimetry, J. Geophys. Res. Oceans, 122, 539-554, doi:10.1002/ 2016JC012487.

Received 18 OCT 2016 Accepted 22 DEC 2016 Accepted article online 29 DEC 2016 Published online 25 JAN 2017

(c) 2016. American Geophysical Union. All Rights Reserved.

\section{Mapping the nonstationary internal tide with satellite altimetry}

\author{
Edward D. Zaron' ${ }^{\text {iD }}$ \\ ${ }^{1}$ Department of Civil and Environmental Engineering, Portland State University, Portland, Oregon, USA
}

\begin{abstract}
Temporal variability of the internal tide has been inferred from the 23 year long combined records of the TOPEX/Poseidon, Jason-1, and Jason-2 satellite altimeters by combining harmonic analysis with an analysis of along-track wavenumber spectra of sea-surface height (SSH). Conventional harmonic analysis is first applied to estimate and remove the stationary components of the tide at each point along the reference ground tracks. The wavenumber spectrum of the residual SSH is then computed, and the variance in a neighborhood around the wavenumber of the mode- 1 baroclinic $M_{2}$ tide is interpreted as the sum of noise, broadband nontidal processes, and the nonstationary tide. At many sites a bump in the spectrum associated with the internal tide is noted, and an empirical model for the noise and nontidal processes is used to estimate the nonstationary semidiurnal tidal variance. The results indicate a spatially inhomogeneous pattern of tidal variability. Nonstationary tides are larger than stationary tides throughout much of the equatorial Pacific and Indian Oceans.
\end{abstract}

\section{Introduction}

Baroclinic, or internal, tides are inertia-gravity waves at tidal frequencies which are generated by the barotropic tide at underwater topography [Garrett and Kunze, 2007]. In situ observations of internal tides using current meters or temperature profiles typically exhibit significant temporal variability [Magaard and McKee, 1973; Barnett and Bernstein, 1975; Weisberg et al., 1987]. In contrast to the variability of tides observed in situ, observations with satellite altimeters have found remarkable phase stability in the baroclinic tides as expressed in sea-surface height (SSH) [Ray and Mitchum, 1996]. Indeed, a significant fraction of the signal must be phase-locked (stationary) in order to identify it with the 10 day sampling of the TOPEX/Poseidon, Jason-1, and Jason-2 (T/P-J) altimeters [LeProvost, 2001]. The contrast between in situ and remotely sensed baroclinic tides is attributed to the sensitivity of measurements based on $\mathrm{SSH}$, which preferentially filters out the higher modes [Hendershott, 1981]. This view is supported by observations using other measurement techniques that combine spatial and phase-averaging to yield phase-coherent baroclinic tidal signals [Dushaw et al., 1995].

Nonetheless, there are good indications that low-frequency processes can modulate the low-mode internal tides and cause detectable changes in tidal SSH. Models of baroclinic tidal propagation that incorporate mesoscale variability find that even the fastest, mode-1, internal tide is affected, particularly with increasing distance from the source regions [Dunphy and Lamb, 2014]. Observations with diverse instruments, such as inverted echo sounders [Chiswell, 2002], tide gauges [Colosi and Munk, 2006], and altimeters [Ray and Zaron, 2011], have been interpreted as exhibiting mode-1 baroclinic tidal variability.

When harmonic analysis is used, only the tidal signal that is coherent with the astronomical forcing over the entire analysis period can be identified, leaving unknown the tidal variability at time scales shorter than the analysis period. Although a near-global view of sea level is available from the T/P-J satellites after every orbit repeat period, the satellites are relatively inefficient at identification of the main semidiurnal tides. The problem, of course, is that the dominant tides are aliased to longer periods by the once-per-10 day sampling, so that it takes 60 days or more to identify semidiurnal tidal variability, and 3 years or more to stably separate the $\mathrm{M}_{2}$ and $\mathrm{S}_{2}$ constituents [e.g., LeProvost, 2001].

Nonastronomical variability in tides has been identified in tide gauge data at a wide range of time scales, ranging from weeks to decades, but analyses are necessarily limited to specific regions or coastal sites [e.g., Kang et al., 1995; Zaron and Jay, 2014]. Using satellite altimetry, the annual cycle of semidiurnal variability may be mapped [Muller et al., 2014], but analyses of variability on shorter time scales is available, once 
again, only at specific sites [Ray and Zaron, 2011; Zhou et al., 2015], or for spatial average tidal properties [Zaron, 2015]. Studies with numerical models suggest that tidal variability attributed to the mode-1 internal tide should be spatially variable and related to the mesoscale eddy field [Zaron and Egbert, 2014; Shriver et al., 2014; Ponte and Klein, 2015; Kelly et al., 2015].

The objective of the present work is to answer the question posed in Ray and Zaron [2011], "How much tidal variability is missed by altimetry?" There are three application areas which motivate the reconsideration of this question. First, for the forthcoming SWOT altimeter mission it will be necessary to remove baroclinic tidal signals in order to study small-scale geostrophically-balanced flows and achieve the science goals of the mission [Fu and Ferrari, 2008]. Satellite altimetry is essentially the only means available to map, nearly globally, the baroclinic tides for developing these models, and it is crucial to quantify the tidal signals not present in these maps [Dushaw, 2015; Egbert et al., 2012; Ray and Zaron, 2016; Zaron, 2014; Zhao et al., 2016]. Second, the low-mode baroclinic tide is the principal pathway through which energy lost from the barotropic tide is transferred to smaller scales in the deep ocean [Egbert and Ray, 2000], so closing the tidal energy budget requires knowledge of both the coherent and incoherent baroclinic tide. And, lastly, the validation of high-resolution numerical models incorporating tides [Arbic et al., 2010] requires data on tidal processes for which there are no sources comparable to altimetry in its near-global coverage.

\section{Identification of the Nonstationary Tide in the Wavenumber Domain}

As described in Ray and Zaron [2011], the wavenumber spectrum of SSH taken along a satellite ground track may be used to identify internal tides, which are evident as the bump in the power spectrum near the wavelength of the mode- 1 internal tide. Figure 1 illustrates the basic idea using data from a satellite track in the Southeast Atlantic, a region of low mesoscale sea level variability. The wavenumber spectrum is here computed by averaging the Hann-windowed periodograms of SSH for the same $2000 \mathrm{~km}$ segment of each orbit cycle. Three versions of the spectrum are shown. In the first version, $S_{0}(k)$, the standard corrections for environmental path delays, mean sea level, sea-state bias, inverse barometer effect, solid earth tides, and barotropic ocean tides have been applied to the satellite range to obtain SSH. The peak at $k_{M 2}$, the wavenumber of the mode- 1 baroclinic $M_{2}$ tide, is evident. The second version of the spectrum, $S_{1}(k)$, is computed with SSH data from which an estimate of the mesoscale sea level anomaly (SLA) has been removed [Ray and Byrne, 2010; Ray and Zaron, 2016]. This spectrum is much flatter and makes the mode- 1 tidal peak even more prominent relative to the background spectrum. Once the mesoscale SLA has been removed, the SSH records are harmonically analyzed within $6.6 \mathrm{~km}$-bins along the average ground track [Ray, 1998; Carrère et al., 2004], and these harmonic constants are used to further correct the SSH data by removing the stationary component of the tide at the $\mathrm{M}_{2}, \mathrm{~S}_{2}, \mathrm{~N}_{2}, \mathrm{~K}_{2}, \mathrm{~K}_{1}, \mathrm{O}_{1}, \mathrm{P}_{1}$, and $\mathrm{Q}_{1}$ frequencies (note that the mean sea level, $Z_{0}$, and the $M_{4}$ overtide are also included in the analysis). The spectrum of the residual, $S_{r}(k)$, is now very flat, except for the bump around $k_{M 2}$ attributed to nonstationary semidiurnal tides.

Determination of the amplitude of the stationary and nonstationary mode- 1 internal tide in this example is relatively straightforward. The stationary component consists primarily of the mode- 1 baroclinic component, but it also contains a small component due to error in the barotropic tide model used for initially correcting the SSH data. The nonstationary component of the variance is hypothesized to be the variance associated with the bump which lies above the broadband continuum. Variance in the broadband continuum consists of ocean variability, instrument noise, and error in the corrections applied to the SSH. As there is no widely-applicable model for these processes, there is some subjectivity in estimating the broadband continuum in order to subtract it from the residual spectrum. The approach taken here is to estimate the broadband continuum with a model spectrum that is a greatest lower bound of the residual spectrum and compute variance by integrating between wavenumbers $k_{1}$ and $k_{2}$ bracketing the internal mode- 1 wavenumber. The model spectrum is a straight line in log-transformed coordinates, $S_{m}(k)=\bar{S}_{m} k^{p}$, and coefficients $\bar{S}_{m}$ and $p$ could, in principle, be chosen so that $S_{m}(k)$ passes through local minima of $S_{1}(k)$ closest to $k_{M 2}$. When the residual spectrum is steeply sloped, this approach is unstable, and better results are obtained by first adjusting the spectrum to remove the large-scale trend by fitting a low-order polynomial to the logtransformed spectrum. Then, minima of the adjusted spectra are more stably identified, and $S_{m}(k)$ is determined by the line passing through the minima on either side of $k_{M 2}$. The minima defining $\left[k_{1}, k_{2}\right]$ are found by searching within a window from $33 \%$ below to $15 \%$ above $k_{M 2}$. These bandwidth search limits were 

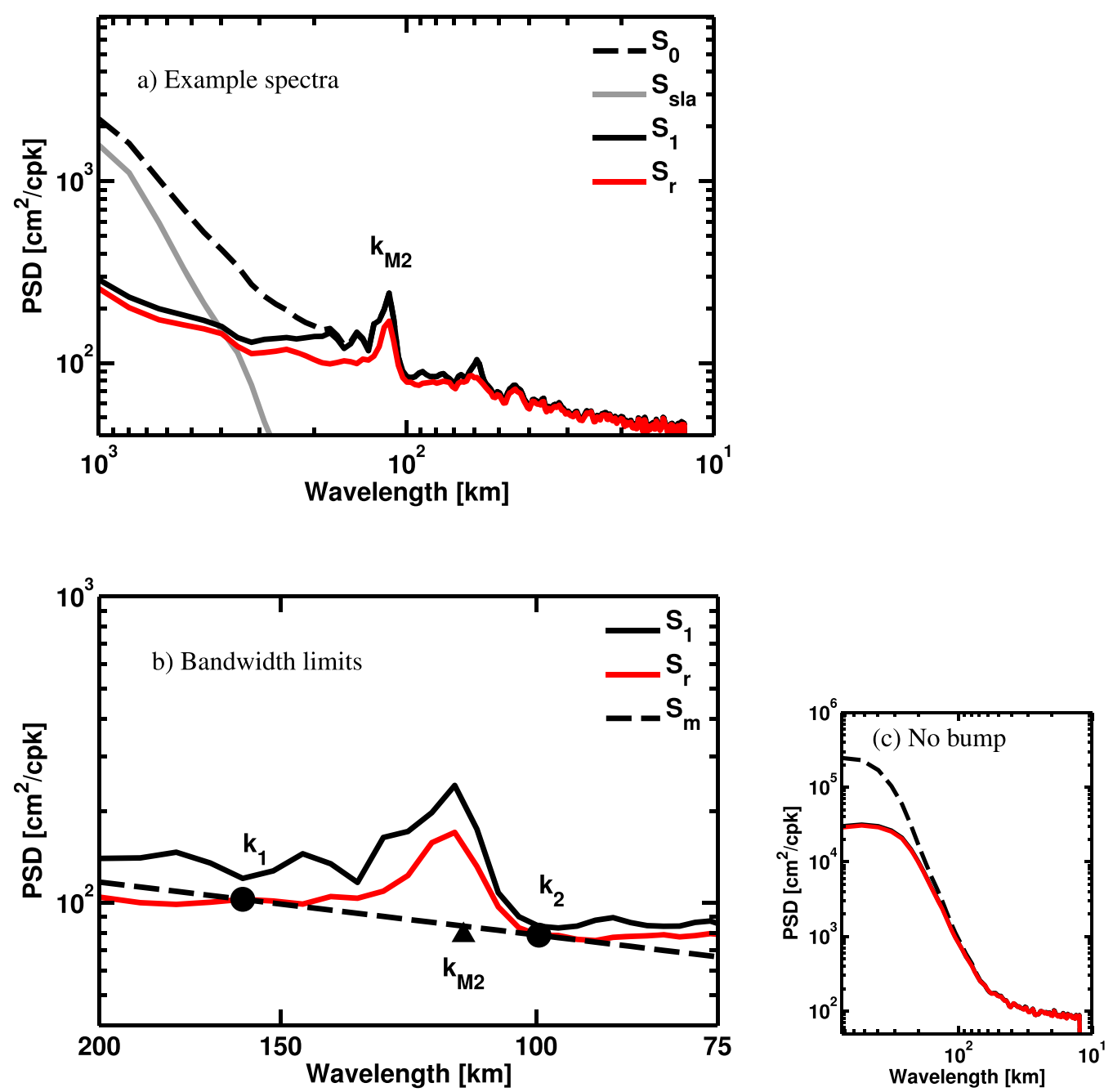

Figure 1. Example spectra from the Southeast Atlantic. (a) The spectrum of $\mathrm{SSH}, \mathrm{S}_{0}(k)$ (uses all standard corrections, including removal of the barotropic ocean tide); the spectrum of the mesoscale correction, $S_{s l a}(k)$; the spectrum of SSH incorporating the mesoscale correction, $S_{1}(k)$; and the spectrum of the mesoscale corrected SSH with coherent tides removed (residual SSH), $S_{r}(k)$. The peak in $S_{1}(k)$ coincides with the theoretically-predicted wavelength of the mode- 1 baroclinic $M_{2}$ tide, marked $k_{M 2}$. (b) The enlarged region around $k_{M 2}$ (marked with the triangle) showing the bandwidth limits, $\left[k_{1}, k_{2}\right]$, and the model spectrum for the nontidal broadband, $S_{m}(k)$. The stationary tidal variance, $\sigma_{c}^{2}$, is equal to the area between the black and red curves. The nonstationary tidal variance, $\sigma_{i}^{2}$, is equal to the area between the red curve and the dashed line. (c) Example from the Gulf Stream region where no spectral bump is visible.

chosen to allow the possibility of capturing variance from waves propagating nonparallel to the ground track, as well as variance at higher wavenumbers which might be present due to leakage from a sharp peak at $k_{M 2}$. The wavenumber $k_{M 2}$ is computed by solving the Sturm-Liouville problem for the vertical modes over flat topography using climatological mean stratification [Ray and Zaron, 2016].

For the example shown in Figure 1 the standard deviation of the stationary semidiurnal tide, computed as the sum of contributions from $\mathrm{M}_{2}, \mathrm{~S}_{2}, \mathrm{~N}_{2}$, and $\mathrm{K}_{2}$ integrated over the $\left[k_{1}, k_{2}\right]$ wavenumber band, is $\sigma_{c}=0.36$ $\mathrm{cm}$. This tiny value illustrates the precision with which the stationary tides may be estimated when the suite of corrections described above are applied (the formal standard error estimated from the harmonic analysis is about $0.1 \mathrm{~cm}$ ). The standard deviation of the residual minus the model broadband spectrum is $\sigma_{i}=0.48$ $\mathrm{cm}$ when integrated over the same wavenumber band. This value of $\sigma_{i}$ is taken as the estimate of the size of the nonstationary tide. The total semidiurnal band baroclinic tidal variance is, $\sigma_{t}^{2}=\sigma_{c}^{2}+\sigma_{i}^{2}$. In this case, the incoherent fraction, defined as $f_{i}=\sigma_{i}^{2} / \sigma_{t}^{2}$, is rather large, $f_{i}=0.64$. Note that the size metrics used here are computed from SSH variance, and the variance is equal to one-half the squared amplitude of a harmonic constant. 
The above-described approach to inferring the nonstationary tide is based on the presence of an identifiable bump or excess of variance in the wavenumber spectrum. In some regions, no bump is visible (Figure 1c). In order to see where this approach is applicable two metrics of the spectrum have been developed to discriminate the presence or absence of a bump. In both cases the $M_{2}$ band is compared with the white noise component of the spectrum, which is defined here by the spectral properties between $k_{\epsilon}=2 \pi /(30 \mathrm{~km})$ and the Nyquist wavenumber $k_{N}=\pi /(6.6 \mathrm{~km})$. The first metric is the ratio of variance in excess of the broadband model versus the noise variance of the spectrum, $B^{2}=\sigma_{B}^{2} / \sigma_{\epsilon}^{2}$, where $\sigma_{B}^{2}$ is,

$$
\sigma_{B}^{2}=\int_{k_{1}}^{k_{2}}\left(S_{1}(k)-S_{m}(k)\right) d k,
$$

and $\sigma_{\epsilon}^{2}$ is,

$$
\sigma_{\epsilon}^{2}=\frac{k_{N}}{k_{N}-k_{\epsilon}} \int_{k_{\epsilon}}^{k_{N}} S_{1}(k) d k
$$

Note that the variance defined in equation (1), $\sigma_{B}^{2}$, contains contributions from both the stationary and nonstationary tides. The second metric is the ratio of mean-square curvature of the log-scaled spectrum in the $\mathrm{M}_{2}$-band versus the noise curvature, $\hat{B}^{2}=\hat{\sigma}_{B}^{2} / \hat{\sigma}_{\epsilon}^{2}$, where $\hat{\sigma}_{B}^{2}$ is,

$$
\hat{\sigma}_{B}^{2}=k_{M 2}^{-1} \int_{0.5 k_{M 2}}^{1.5 k_{M 2}}\left(\frac{d^{2} \ln \left(S_{1}(k)\right)}{d k^{2}}\right)^{2} d k,
$$

and $\hat{\sigma}_{\epsilon}^{2}$ is,

$$
\hat{\sigma}_{\epsilon}^{2}=\left(k_{N}-k_{\epsilon}\right)^{-1} \int_{k_{\epsilon}}^{k_{N}}\left(\frac{d^{2} \ln \left(S_{1}(k)\right)}{d k^{2}}\right)^{2} d k .
$$

As shown in Figure 2a, the quantity $B$ is greater than one throughout much of the Tropical and Subtropical Pacific and Atlantic. Essentially all the main internal tide generation sites identified in previous satellite studies occur in areas where $B>1$. In a large part of the Southern Ocean the $B$ metric is very large, and closer inspection of the spectra in these regions finds that the transition from a flat- to steeply-sloped mesoscale spectrum occurs near $k_{M 2}$ (not shown). In this case the $B$ metric is not a reliable indicator, and, instead, the $\hat{B}$ metric indicates that there is essentially no spectral bump associated with the semidiurnal internal tide in the Southern Ocean (Figure 2b).

In addition to the presence or absence of the spectral bump, there is a bias problem associated with the estimation of the coherent tide from noisy data, and this bias influences the apparent ratio of incoherent to coherent tidal variance. Because the in-phase and quadrature components of the coherent tide are estimated via least-squares, these quantities are un-biased by noise in the data; in other words, the harmonic constants estimated for a time series of pure noise will, on average, be zero. This is not the case, however, for the estimate of the coherent tidal variance (one-half sum of the squared in-phase and quadrature coefficients), this quantity is systematically increased (biased) by noise in the time series. Correcting the bias requires an accurate estimate for the noise, but the sampling variability of the noise variance estimate is generally too large to use it as a correction (cf., Figures 6 and 7 discussed below). Based on the formal error estimate, the average bias in $\sigma_{c}^{2}$ is approximately $0.04 \mathrm{~cm}^{2}$, but this is likely to exhibit strong geographic variations. Rather than use a spatially-constant value, the $\sigma_{c}^{2}$ estimates are left uncorrected, and it should be understood that the amplitude of the coherent baroclinic tides here are slight over-estimates. For typical signals of $1 \mathrm{~cm}$ or larger, the bias is inconsequential, but the interpretation of smaller signals will eventually require a more careful analysis.

\section{Global Summaries}

The above analysis of along track spectra has been conducted on track segments of length $2000 \mathrm{~km}$ centered on orbit crossover points using SSH data from the merged T/P-J missions. Data from other exactrepeat missions has also been analyzed using the same methodology (not shown), but the data quality and record length along the T/P-J reference orbit are superior to that of other missions, leading to much more accurate estimates of the coherent tides. By centering the analysis at crossover points, the results from 

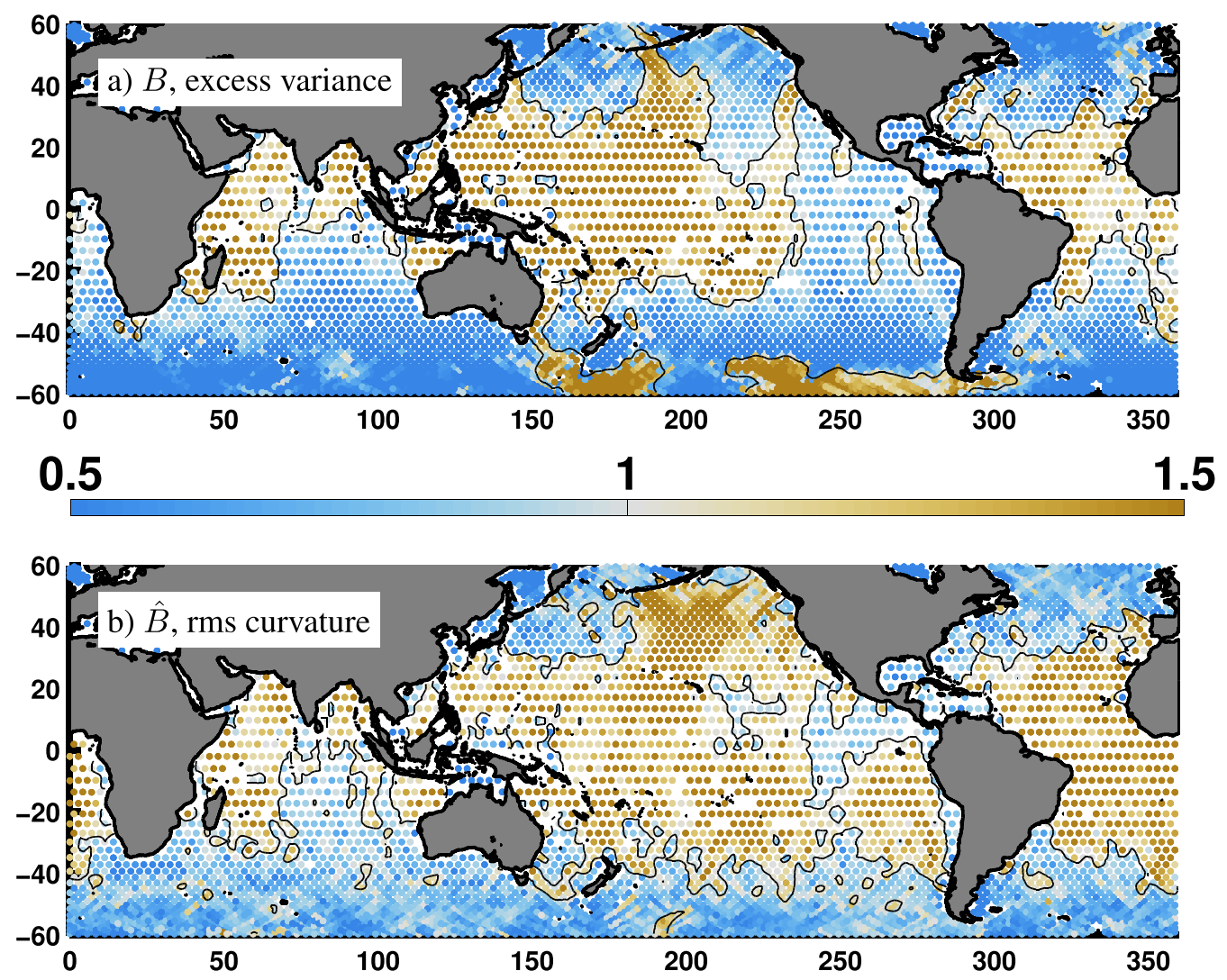

Figure 2. Metrics for the presence of a spectral "bump." (a) $B$ is a measure of excess variance in the $k_{M 2}$ waveband, relative to the broadband mesoscale model spectrum (equation (1)). (b) $\hat{B}$ is a measure of root-mean-square curvature of the log-scaled spectrum (equation (3)). Much of the Southern Ocean, south of $45^{\circ} \mathrm{S}$, has no identifiable peak near $k_{M 2}$. The $B$ metric is unreliable in this area because the $k_{M 2}$ wavenumber band overlaps with the change in slope of the mesoscale spectrum.

ascending and descending tracks can be averaged and conveniently plotted at each crossover point. An additional reason for emphasizing the comparison at crossover points is that independent estimates of the stationary tide are available along the ascending and descending tracks, and these provide a check on the resulting formal error estimates.

For reference, it is useful to begin by summarizing some results from the literature [e.g., Stammer, 1997], but replicated using the statistics of the merged T/P-J records. Figure 3 shows the root-mean-square (rms) sea level variability computed by integrating the raw spectrum, $S_{0}(k)$, less the estimated noise, $S_{\epsilon}=\sigma_{\epsilon}^{2} / k_{N} . \mathrm{SSH}$ variability associated with the western boundary currents and the Circumpolar Current is prominent. The white noise component of the spectrum, $\sigma_{\epsilon}$, is shown in Figure 4. One observes more noise at higher latitudes associated with the storm tracks and higher significant wave height [Yale et al., 1995; Goff, 2009]. In these maps, and those below, individual colored dots are plotted at the crossover points according to the color scale shown. Contours are plotted by smoothly interpolating the crossover data onto a regular grid and then contouring these values. The contoured values coincide with the tick marks displayed on the color scale.

Figure 5 shows the rms coherent tidal signal integrated over the semidiurnal waveband, $\left[k_{1}, k_{2}\right]$, computed by summing the $\mathrm{M}_{2}, \mathrm{~S}_{2}, \mathrm{~K}_{2}$, and $\mathrm{N}_{2}$ components. These spectra are equal to $1 / 2$ the sum of the individual spectra of the in-phase and quadrature harmonic constants, so that an integral of the spectrum equals $\mathrm{SSH}$ variance. The variability is dominated by the $\mathrm{M}_{2}$ component; although, all the semidiurnal constituents have been included since they cannot be separated in the nonstationary tidal estimate, presented below. Variability associated with the internal tide is prominent in association with the Hawaiian Ridge and the Aleutian Islands in the North Pacific, the Luzon Strait and the Mariana Trench in the Western Pacific, Tuomoto and the Solomon Sea in the South Pacific, the Amazon River Delta and the Azores in the Atlantic, and at 

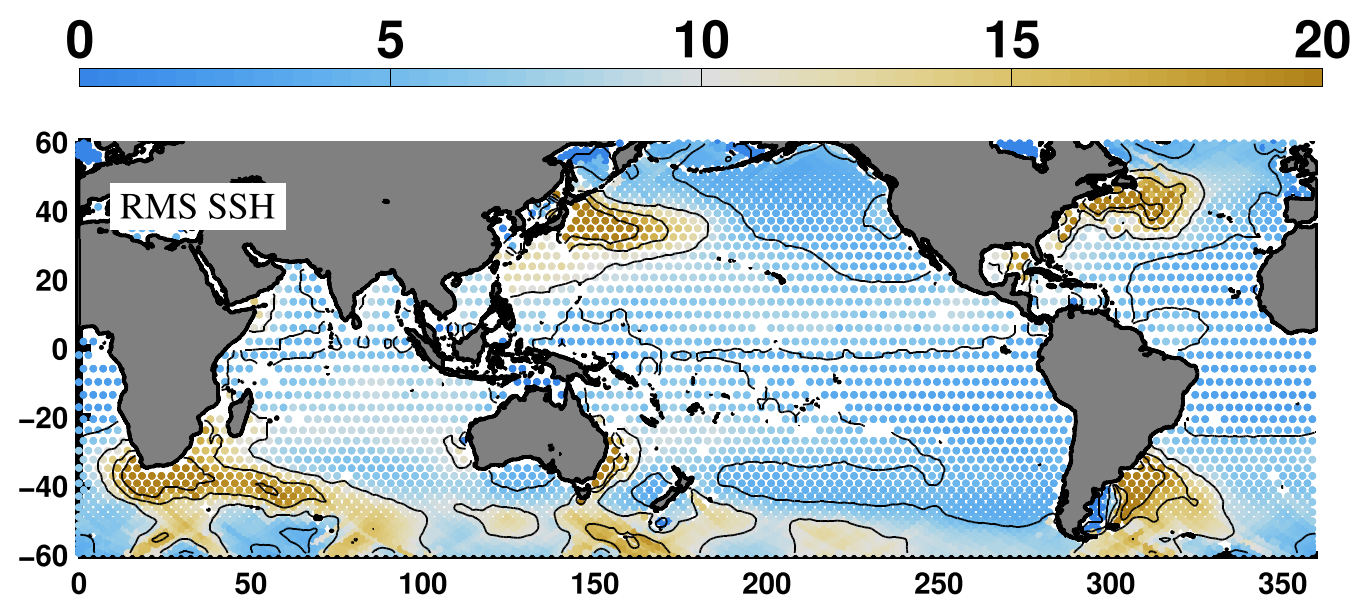

Figure 3. Sea-level variability (rms, centimeters) obtained by integrating the wavenumber power spectrum, $S_{0}(k)-S_{\epsilon}$, from $k=0$ to $k=k_{\epsilon}$.

several other sites around the coast of Africa including north and east of Madagascar, and in the eastern Arabian Sea and eastern Bay of Bengal.

When harmonic analysis is used to estimate the tide at each point along the satellite ground track, one of the outputs of the analysis is an estimate of the uncertainty of the harmonic constants [Carrère et al., 2004], which is here estimated from the residual variance within a Rayleigh bandwidth around the aliased tidal frequencies. In this case, the 23 year long merged T/P-J record was used, so the variance near the tidal alias frequencies includes the nonstationary tide, residual nontidal variance not removed by the mesoscale correction, and variance from higher-frequency processes with aliases in the same tidal band. The map of the standard error shown in Figure 6 indicates that the noise in the harmonic constants is largely correlated with the overall level of sea level variability (Figure 3); although, errors are much lower than they would be if the mesoscale correction had not been applied.

One noteworthy aspect of using an analysis focussed on orbit crossover points is that the uncertainty estimate from the harmonic analysis can be independently validated by comparing the harmonic constants from ascending and descending tracks. The ratio of actual to predicted error is, in theory, distributed like Student's t-statistic, a long-tailed distribution. In this case the median of the sample distribution is close to 1 , which suggests that the estimated error is a valid estimate of the actual error. One-half the absolute vector error is shown in Figure 7, equal to one-quarter of the sum of squared errors in the in-phase and quadrature components, for comparison with the formal error estimate. Some aspects of the spatial pattern of errors is similar, such as increased values in the Southern Ocean and western boundary current regions; but
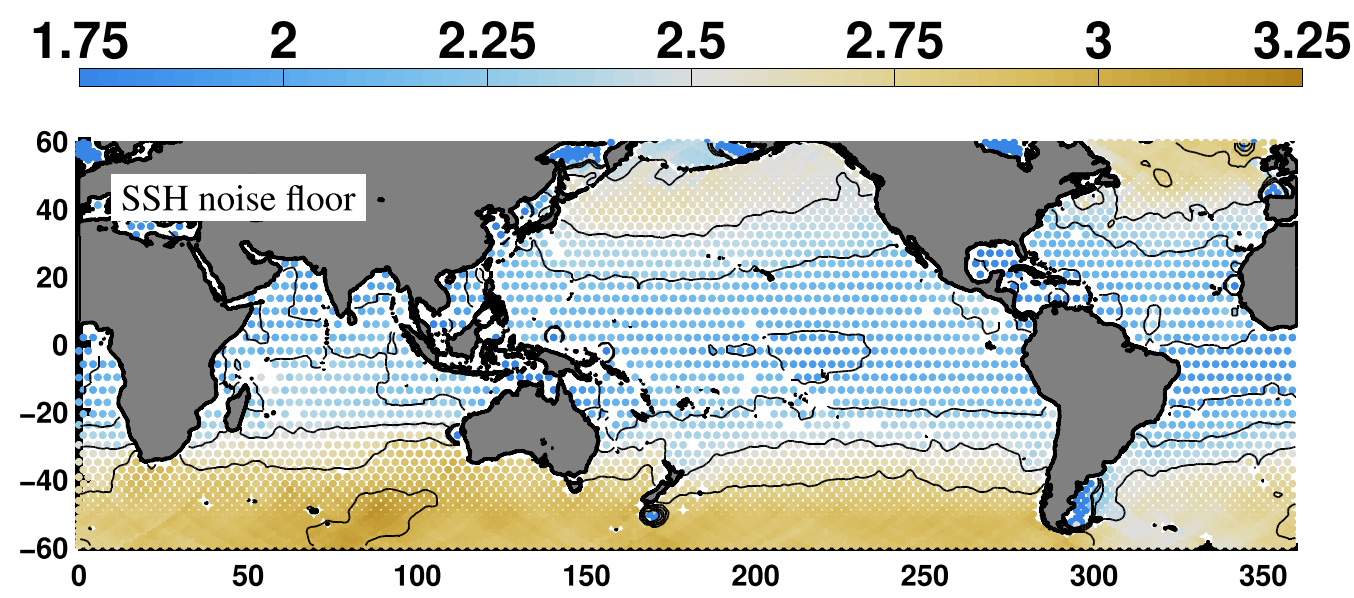

Figure 4. The white noise level of the altimeter spectra ( $\mathrm{rms}$, centimeters) is shown. Oceanic regions with noise off scale, below $1.75 \mathrm{~cm}$, are too close to land or contain too few data to reliably determine the wavenumber power spectrum. 

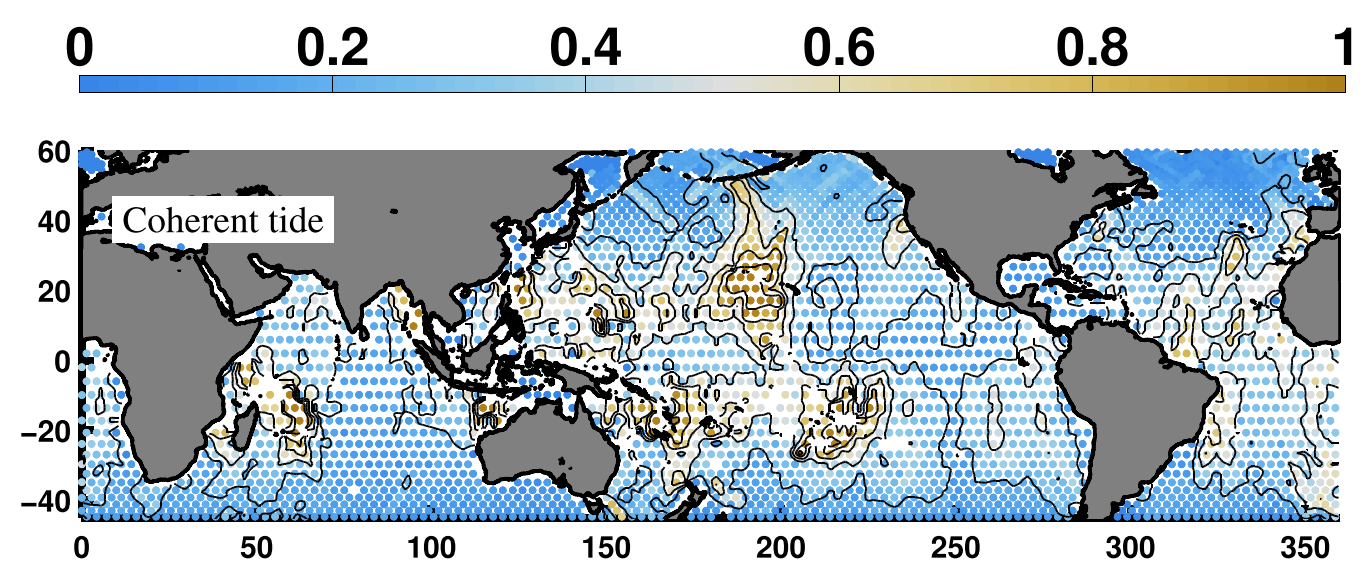

Figure 5. The variability of the coherent tide (rms, centimeters), including contributions from the $M_{2}, S_{2}, K_{2}$, and $N_{2}$ tides.

there are also some differences, such as larger values of the actual error along the west coast of North America, larger errors east of Madagascar, and generally larger values in the western Pacific. The reasons for these differences are not clear, but the residual variance within a Rayleigh bandwidth is based on a simple average [Daniell, 1946] over a bandwidth of $0.4 \mathrm{cyc} / \mathrm{yr}$ (15 Fourier bins). If the nonstationary tide is a significant contributor to the residual variance, the actual error might depend strongly on the bandwidth or statistics of the tidal modulations, making the formal error estimate inaccurate.

Lastly, Figure 8 shows the nonstationary internal tide computed by integrating $S_{r}(k)-S_{m}(k)$ over the $\left[k_{1}, k_{2}\right]$ waveband. Recall that $S_{r}$ is the wavenumber spectrum of SSH corrected for all standard environmental and path delays, including barotropic and baroclinic coherent tides and mesoscale sea level variability, and $S_{m}(k)$ is a simple model for the broadband (nontidal) SSH spectrum. The nonstationary tidal variance is then defined as $\sigma_{i}^{2}$

$$
\sigma_{i}^{2}=\int_{k_{1}}^{k_{2}}\left(S_{r}(k)-S_{m}(k)\right) d k .
$$

The principle features of the nonstationary tide are a large regional maximum in the western equatorial and south-tropical Pacific, and smaller-scale maxima associated with the Amazon River plume, the Bay of Bengal, the Philippine Sea, and the region north of Madagascar. The spatial pattern has some similarity with the pattern of the coherent internal tide (Figure 5), but important differences. The stationary internal tide is very small in the western equatorial Pacific, where the nonstationary tide is large. The stationary tide is large near the Hawaiian Ridge and Polynesia, but these regions are less prominent on the nonstationary tide map. It is also noteworthy that the nonstationary tide is not particularly large in regions of highest SSH variance (Figure 3); although, this may be because the mesoscale is strong enough to effectively obliterate or mask the mode-1 tidal wavenumber peaks in these regions (Figure 2).
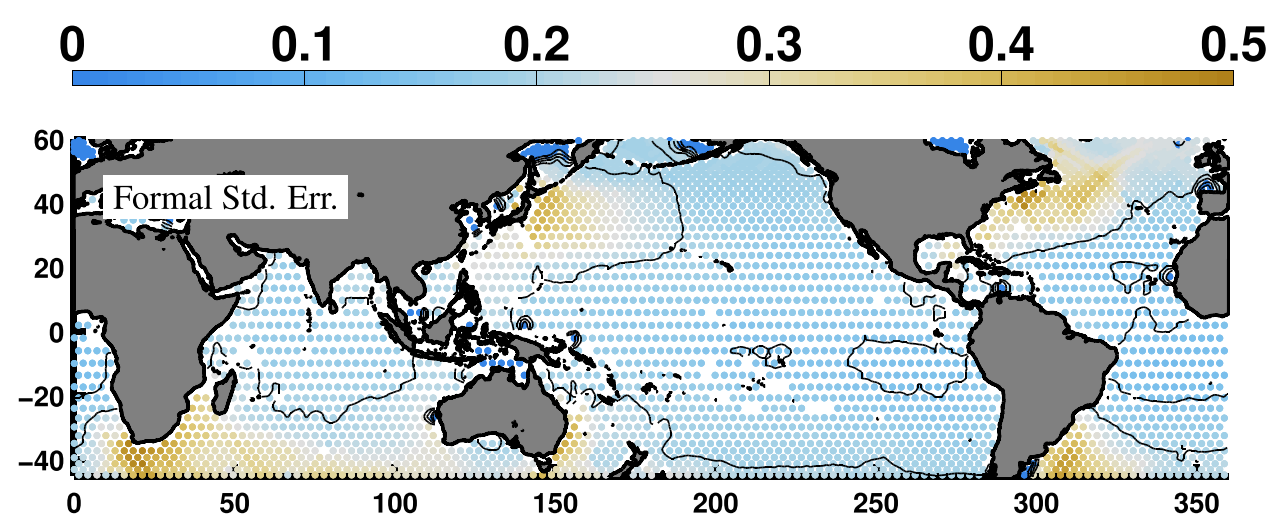

Figure 6. The standard error estimate ( $\sigma_{M 2}$, in centimeters) of the $\mathrm{M}_{2}$ harmonic constant obtained from the harmonic analysis. 

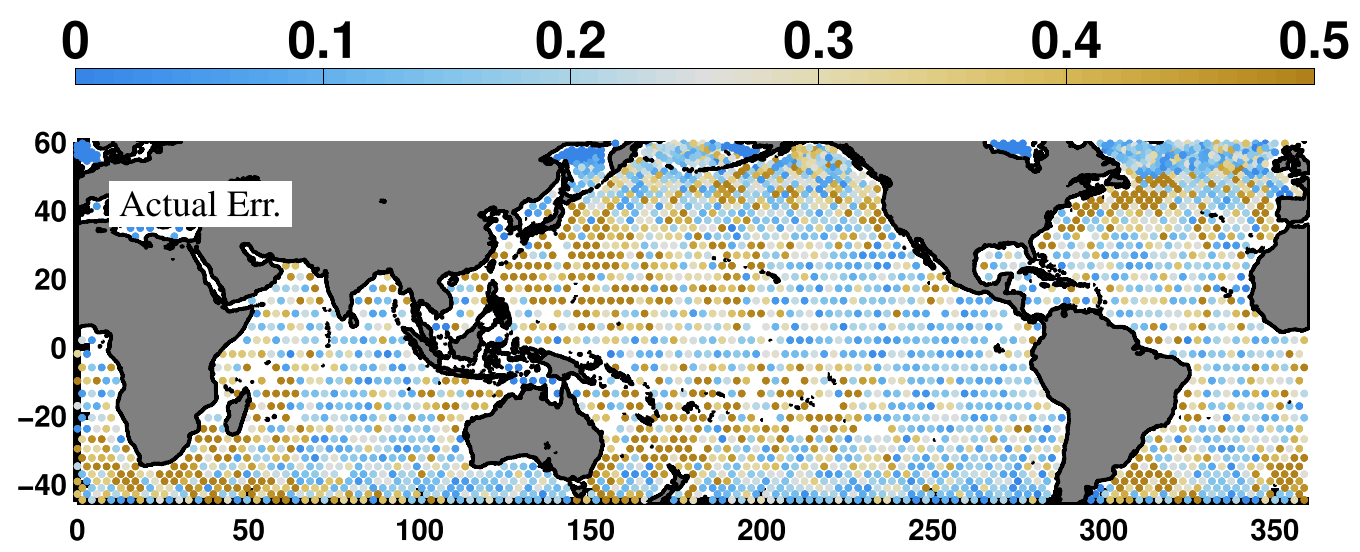

Figure 7. The absolute vector error (centimeters) of the $M_{2}$ harmonic constants as determined by differencing independent estimates from ascending and descending orbit tracks. The absolute vector error is defined to be comparable with the formal error estimate in Figure 6.

Figure 8 provides a provisional answer to the question originally posed concerning the size of the nonstationary internal tide missed by harmonic analyses of altimeter data. Not surprisingly, the size of the nonstationary tide is spatially variable, much like the stationary internal tide. The size of the nonstationary tide is typically smaller than its stationary counterpart; although, there are significant exceptions to this generalization. The fraction of the mode- 1 baroclinic semidiurnal variance associated with the nonstationary component is shown in Figure 9. The variance ratio, $f_{i}=\sigma_{i}^{2} / \sigma_{t}^{2}$, has been slightly smoothed and not plotted where $\sigma_{t}^{2}$ is less than twice the formal error variance computed from the harmonic analysis, $2 \sigma_{M 2}^{2}$. The main feature of this plot is the dominance of the nonstationary tide in the Tropics at nearly all longitudes.

\section{Regional Examples}

Geographic variations in the tidal properties and the broadband nontidal spectrum are large, and it is difficult to assimilate the above near-global summaries without specific examples. The purpose of this section is to review in detail the along-track tidal analyses and wavenumber spectra from a range of sites with different attributes.

\subsection{The Southeast Atlantic}

As already mentioned, the southeast Atlantic Ocean is a region of characteristically low rms SSH variability, less than $5 \mathrm{~cm}$ (Figure 3), and, because of the small significant wave height, a low altimeter noise floor (Figure 4). Figure 10a plots the $M_{2}$ harmonic constants at each point along track, illustrating in the spatial domain the peak of tidal variance associated with the $k_{M 2}$ wavenumber. The SSH spectra $\left(S_{0}, S_{1}\right.$, and $\left.S_{r}\right)$ shown in Figure 10b partially repeat the content of Figure 1, but using the same $y$-axis range as subsequent
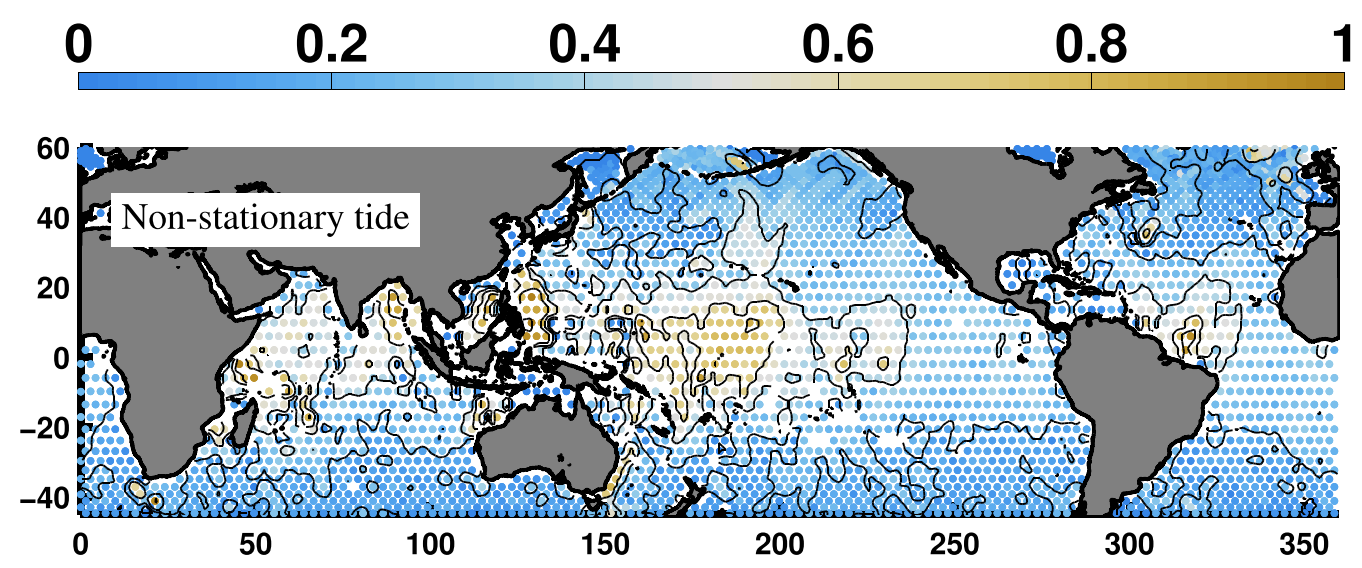

Figure 8. The variability (rms, centimeters) of the nonstationary tide, $\sigma_{i}$, estimated from the along-track wavenumber spectrum (5). 

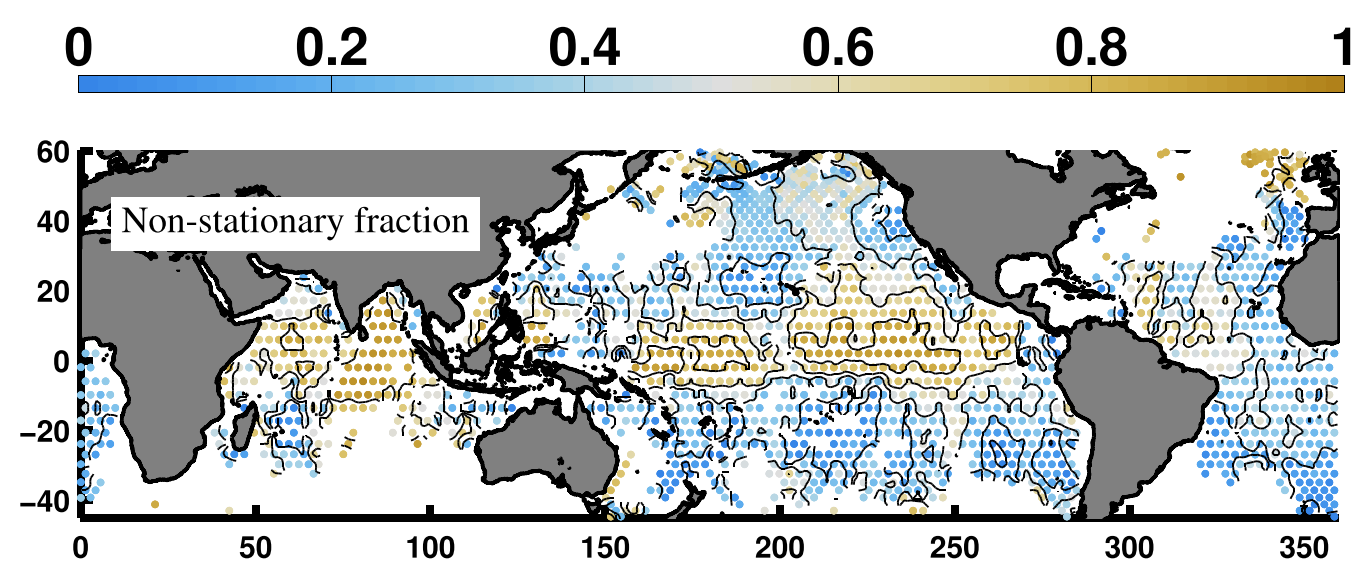

Figure 9. The nonstationary fraction of the mode- 1 baroclinic semidiurnal band variance, $f_{i}=\sigma_{i}^{2} / \sigma_{t}^{2}$. White areas indicate regions where the denominator of this expression is small, $\sigma_{t}^{2}<2 \sigma_{M 2}^{2}$.

plots to facilitate comparison. Figure 10c shows adjusted spectra, $S_{1}-S_{m}$ and $S_{r}-S_{m}$, to illustrate the prominence of the spectral peaks relative to the broadband spectrum $S_{m}$. Figure 10c also shows numeric values of the rms variability of the total $\left(\sigma_{t}\right)$, stationary $\left(\sigma_{c}\right)$, and nonstationary $\left(\sigma_{i}\right)$ components of tidal variability computed over the $\left[k_{1}, k_{2}\right]$ waveband, and, in parentheses, the same quantities computed by integration over the fixed bandwidth $[0.67,1.15] k_{M 2}$. The $x$-axis indicates these wavebands with gray shading and a dashed line, respectively, and the theoretically-predicted value of $k_{M 2}$ is shown with the black triangle.

The purpose of tabulating the rms tidal variabilities using the different bandwidths of integration is to provide some indication of the uncertainty of these quantities as a function of the bandwidth. In cases such as shown in Figure 10, the uncertainty is low since the bump in $S_{1}$ is unambiguous, and $k_{1}$ and $k_{2}$ are welldefined local minima.

\subsection{The Northwest Atlantic}

The northwest Atlantic Ocean is a region of characteristically high rms SSH variability, greater than $20 \mathrm{~cm}$ (Figure 3), and with conditions very different from the Southeast Atlantic. The along-track harmonic analysis finds $M_{2}$ tidal signals that are barely larger than the formal error bars (Figure 11a), and the actual error diagnosed from ascending and descending tracks is much larger (Figure 7). As expected under these conditions, there is no internal tide peak visible in the wavenumber spectrum (Figure 11b).
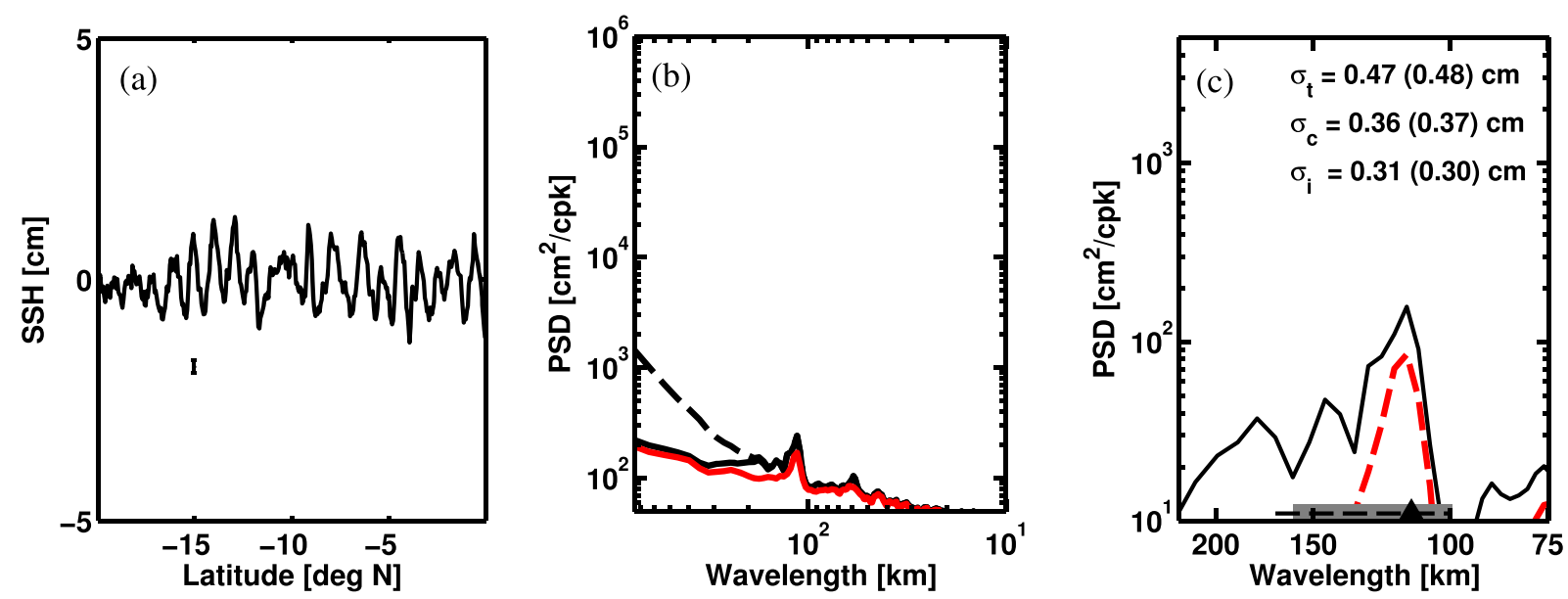

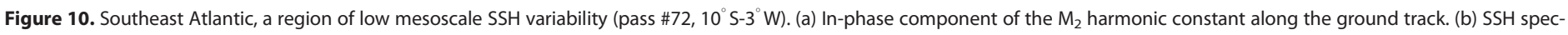

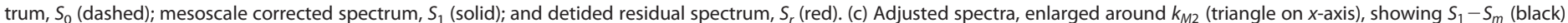

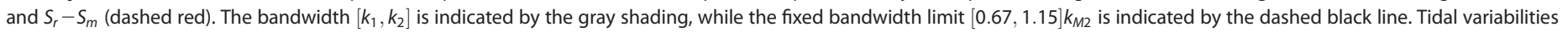
based on integration over $\left[k_{1}, k_{2}\right]$ are given (values in parentheses are integrals over $[0.67,1.15] k_{M 2}$ ). 


\section{CAGU Journal of Geophysical Research: Oceans}
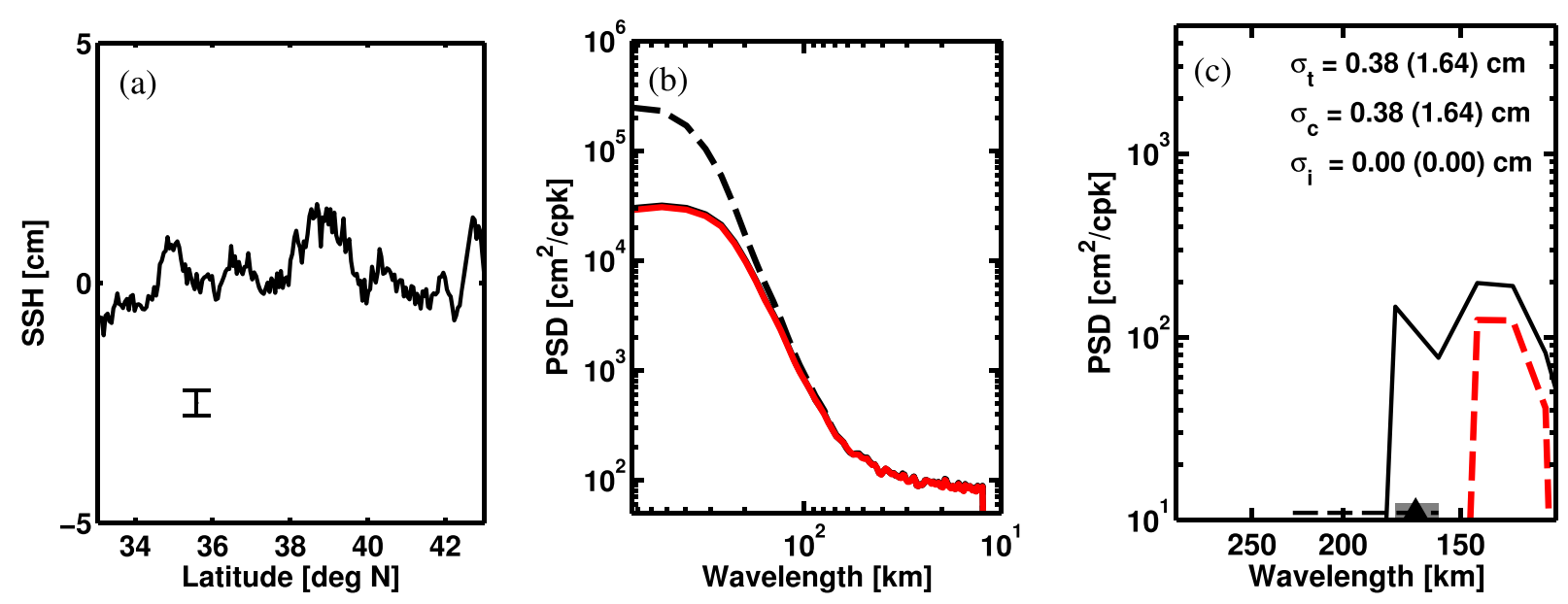

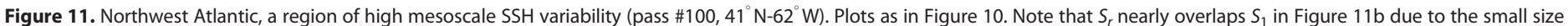
of the coherent tide.

\subsection{The Coral Sea}

The Coral Sea provides an example of a region with moderate mesoscale variability which would normally mask the spectral bump due to tides if it were not for the mesoscale correction. The region is also interesting because the along track tidal analysis removes variance at scales significantly longer than the mode- 1 wavelength (Figures 12a and 12b). Presumably this is associated with internal tides propagating at different angles to the ground track. The change in wavelength between the north and south part of the track (Figure 12a) indicates the spatial variability of the internal tide properties. Both of these attributes are consistent with in situ observations in this region [Wolanski and Pickard, 1983; Boettger et al., 2015].

The variance under the mesoscale-corrected spectrum is visibly reduced by subtraction of the coherent tide along this track (Figure 12b). The curvature of the residual $S_{r}$ spectrum makes it difficult to justify any particular choice of model for the broadband continuum but it is evident that nonstationary tides are either very small or distributed over a wide bandwidth (Figure 12c).

\subsection{The Mascarene Ridge/Seychelles-Maritius Plateau}

Some of the largest internal tides in the world are generated on the flanks of the Mascarene Ridge in the Western Indian Ocean [Konyaev et al., 1995; Morozov and Vlasenko, 1996]. At the edge of the ridge, the seasurface expression of the internal tide is nearly $10 \mathrm{~cm}$ (the peak-to-peak range of the in-phase component in Figure 13a exceeds $5 \mathrm{~cm}$ ). Like the Coral Sea, this is a region in which the coherent tidal correction removes variance at a wide range of wavelengths. Part of the correction may be attributed to the barotropic
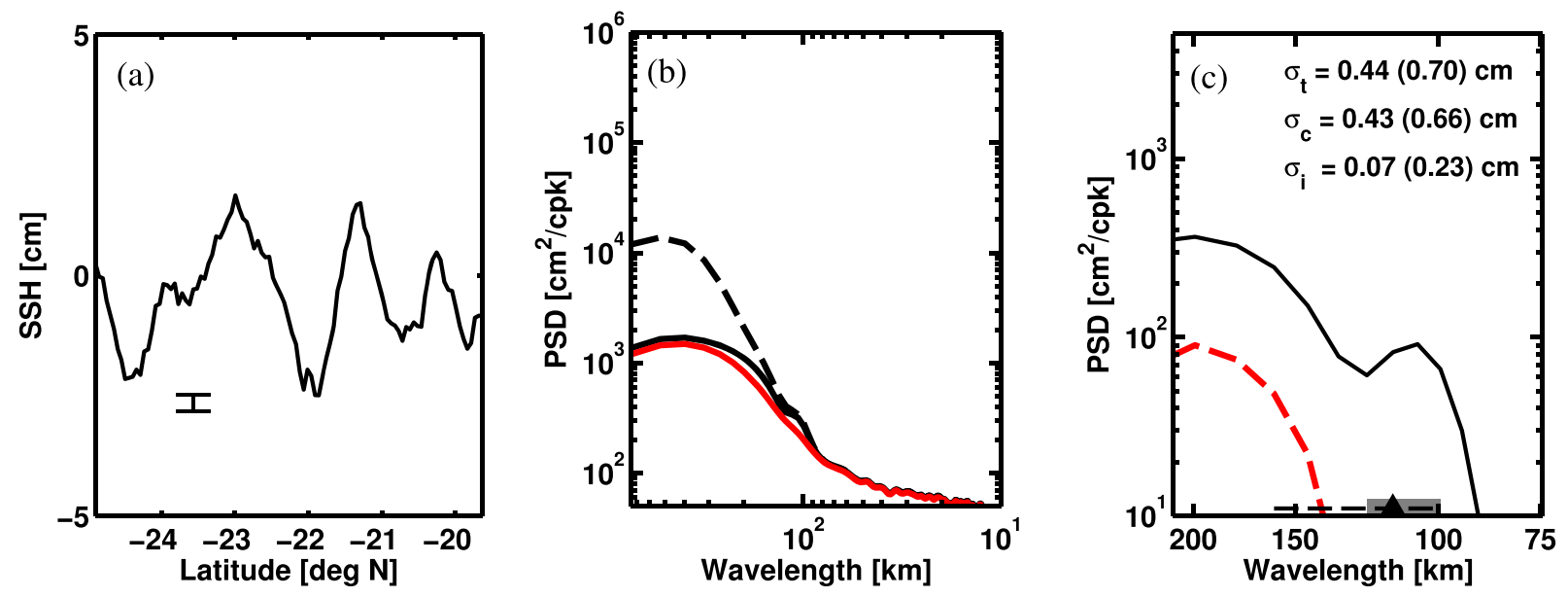

Figure 12. Coral Sea, a region with moderate mesoscale (pass \#10, $17^{\circ} \mathrm{S}-159^{\circ} \mathrm{E}$ ). Plots as in Figure 10. 

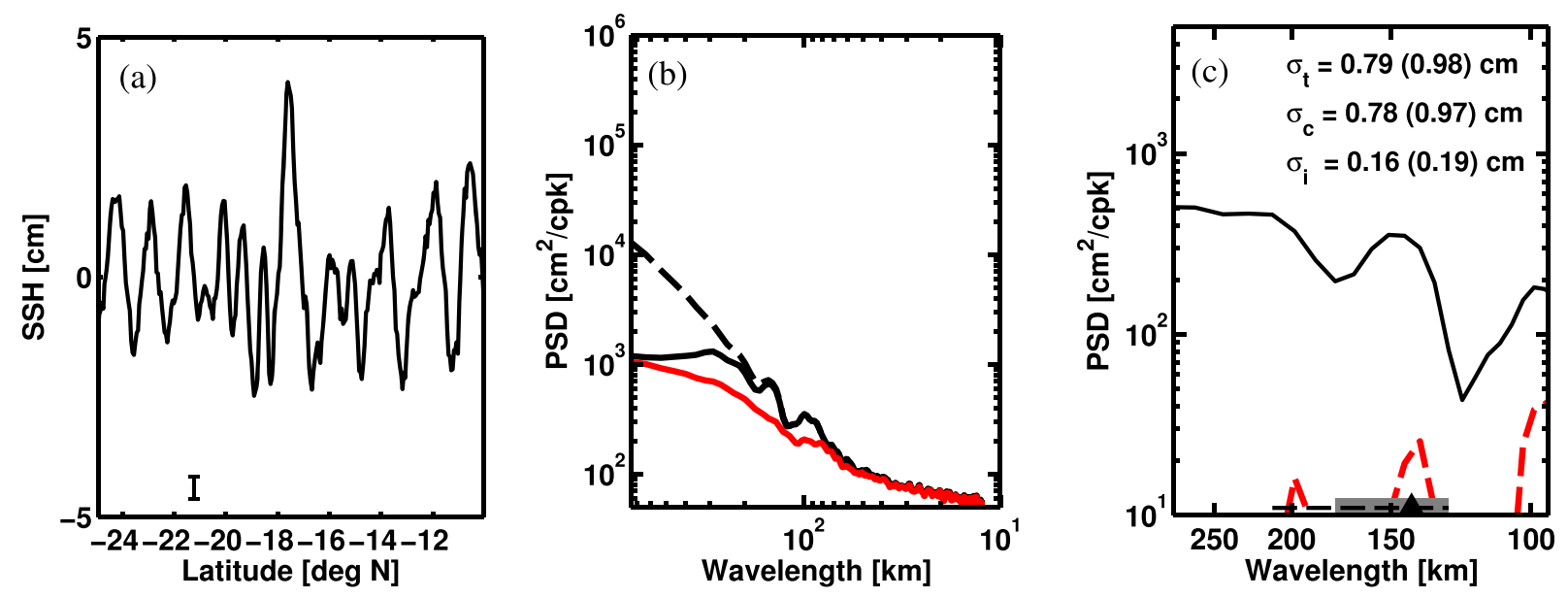

Figure 13. Seycheles-Maritius Plateau, a region with some of the largest stationary baroclinic tides in the world (pass \#144, $\left.17^{\circ} \mathrm{S}-60^{\circ} \mathrm{E}\right)$. Plots as in Figure 10.

tide, but it may also be that the sea-surface signal is the result of strongly coupled or directly forced modes, rather than freely-propagating baroclinic waves. Once again, the residual spectrum, $S_{r}(k)$, is not smooth enough to justify a particular model for the nontidal broadband, but it is clear than the stationary tide is much larger than the nonstationary tide at this site (Figures $13 \mathrm{~b}$ and $13 \mathrm{c}$ )

\subsection{The Bay of Bengal}

The Bay of Bengal provides an example of a region where nonstationary tides are much larger than stationary tides. The $\mathrm{M}_{2}$ harmonic constants are barely larger than the formal error estimate (Figure 14a), and the power spectrum is not visibly reduced by subtracting the stationary tide (Figure 14b). Tides in the region exceed $1 \mathrm{~m}$ at the coast [Murty and Henry, 1983; Sindhu and Unnikrishnan, 2013], and significant interactions between tides and storm surges occur here [Antony and Unnikrishnan, 2013]. It might be speculated that the tidal nonstationarity is caused by nonlinear interactions of the barotropic tide with nontidal processes; however, the power spectrum is very clearly peaked at $k_{M 2}$ and suggests that quasi-linear internal tides are responsible for the variability. Internal tides in the Eastern Bay of Bengal, and much of the Northern Hemisphere Indian Ocean, are dominated by the nonstationary component, suggesting that this region would provide a good case study for investigating the dynamics and time scales of the nonstationary tide.

\subsection{The Western Equatorial Pacific}

One conspicuous feature of previous analyses of the internal tides from altimetry is the apparent dissipation of internal tides radiated southward from the Hawaiian Ridge and northward from the Tuomoto
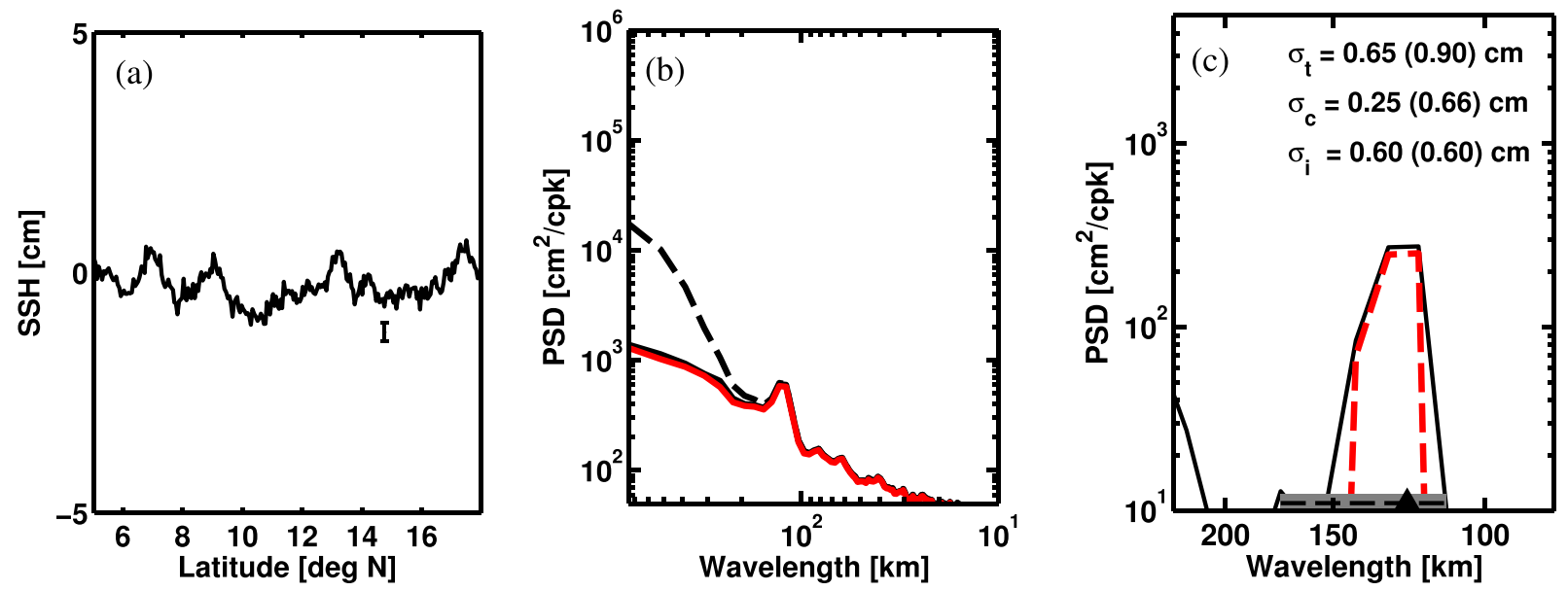

Figure 14. The Bay of Bengal, a region with large nonstationary internal tides (pass \#53, $13^{\circ} \mathrm{S}-88^{\circ} \mathrm{E}$ ). Plots as in Figure 10. 


\section{QAGU Journal of Geophysical Research: Oceans}
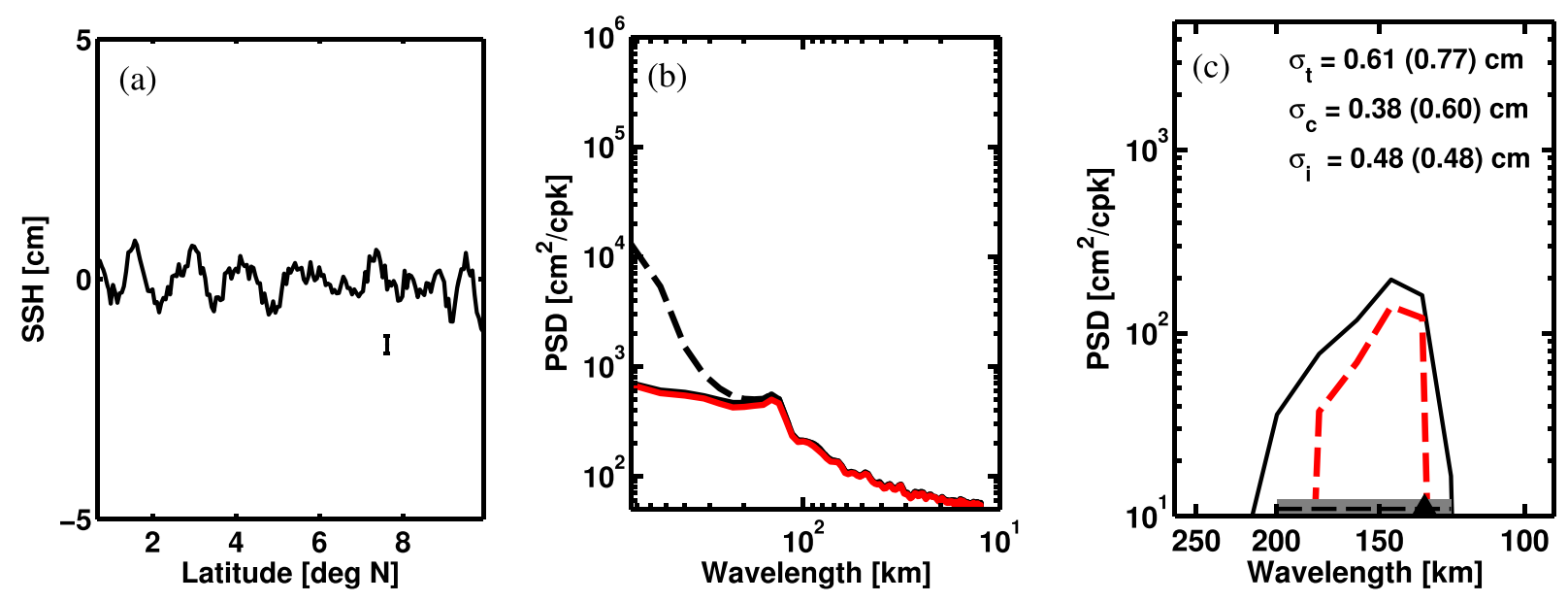

Figure 15. The western equatorial Pacific, a large region where nonstationary internal tides are larger than stationary internal tides (pass \#199, $2^{\circ}$ S- $173^{\circ} \mathrm{E}$ ). Plots as in Figure 10.

Archipelago [Zhao et al., 2016]. Analyses of internal tides at $156^{\circ} \mathrm{E}$ in the western equatorial Pacific have reported large amplitude and variable internal tides propagating from the nearby sites [Gourdeau, 1998]. Further to the east, there is a large area of the western equatorial Pacific in which nonstationary tides are as large or larger than stationary tides (Figure 8).

Figure 15 illustrates typical features of this region. The stationary baroclinic tides are not much larger than the standard errors (Figure 15a), but the signal is coherent along-track, and it is clearly associated with the mode-1 wavenumber (Figure 15b). The spectral bump associated with the nonstationary tide stands out well above the broadband continuum in this region, but even here the relative fraction of nonstationary variability is sensitive to the bandwidth of integration (Figure 15c).

\section{Discussion}

The above estimates of the nonstationary tide were limited to analysis of semidiurnal tidal frequencies and wavenumbers associated with the mode- 1 baroclinic tide. Systematic analysis of diurnal tides is problematic because the signal is generally smaller than in the semidiurnal band and it coincides with a more energetic part of the mesoscale spectrum. Nonetheless, as mentioned in Ray and Zaron [2011], there are clearly some sites where diurnal band modulations can be identified. The restriction to the mode- 1 semidiurnal wave band has also excluded both barotropic and higher-mode baroclinic tidal variability; although, it is conceivable that some mode- 2 diurnal variability overlaps in this band. In any event, the maps of the nonstationary tide presented here should be regarded as a lower bound on nonstationary tidal variability.

There are several sources of systematic uncertainty that might bias the estimates of nonstationary tidal variability. For example, if the amplitude of the nontidal broadband spectrum is over-estimated by the model, $S_{m}(k)$, it would lead to a systematic under-estimation of the nonstationary tidal variance. If the nontidal spectrum consists entirely of a steeply-sloped spectrum, e.g., $k^{-3}$ or $k^{-11 / 3}$ associated with geostrophic or surface quasi-geostrophic turbulence, respectively [LeTraon et al., 2008], then the nonstationary variance may be greatly under-estimated. Alternately, it is conceivable that the broadband spectrum results from quasi-linear internal gravity waves $\left(k^{-2}\right.$, LeTraon et al., 1990) or stratified turbulence $\left(k^{-5 / 3}\right.$, Kitamura and Matsuda, 2006). In these cases, the nonstationary tide inferred from the wavenumber spectrum would not be grossly under-estimated. Other models for the broadband nontidal variance were also examined (not shown) [Fu, 1983; LeTraon et al., 1990; Stammer, 1997; Glazman and Cheng, 1999; LeTraon et al., 2008; Xu and $F u, 2011]$, but parametric fits to $S_{0}(k)$ with a prescribed theoretical form were generally not satisfactory. Regression of $S_{1}(k)$ or $\log -S_{1}(k)$ using low-order polynomials over the spectrum both above and below the wavenumber bump are more satisfactory, but tend to be sensitive to the curvature of the spectrum in the mesoscale range, leading to unstable estimates for variance in the tidal band. It seems likely that different processes are responsible for the nontidal spectrum in different regions [ $X u$ and $F u, 2011]$. 
Another potential source of error in the present approach is tidal contamination of the mesoscale correction. The 2014 version of the Ssalto/Duacs multisatellite gridded sea-level anomaly (SLA) product contains a signal indistinguishable from the alias of the mode- 1 baroclinic $M_{2}$ tide [Ray and Zaron, 2016]. The rms magnitude of the signal exceeds $0.5 \mathrm{~cm}$ at some locations and presents a problem for analysis of internal tides in altimetry data collected since 2014. To ameliorate this problem a filtered version of the 2014 SLA product was prepared which reduces tidal contamination to roughly the same level as in the older product. The filtering is implemented as a symmetric auto-regressive time filter with 60 day half-power point [Bennett, 2002, pp. 65-66] combined with a spatial filter with $170 \mathrm{~km}$ correlation scale [Mirouze and Weaver, 2010]. The internal tide contamination in the filtered version is reduced to a negligible level for the present study, but further study is needed to examine tidal contamination near coasts and at high latitudes.

It is interesting to compare the map of nonstationary semidiurnal variability (Figure 8) with a similar map of the baroclinic $M_{2}$ variability from Carrère et al. [2004]. The latter was computed from changes in the $M_{2}$ harmonic constants determined from nonoverlapping, but consecutive, 3 years. periods of TOPEX/Poseidon data. The present analysis is based on a longer record and includes the mesoscale correction, so the over-all noise level of the harmonic constants is much lower. Even allowing for this, the older work shows an absence of variability connected to the Amazon River Plume, the Tropical Pacific, and the Bay of Bengal. The conclusion from this comparison is that much of the variability of the internal tide occurs on time scales shorter than 3 years, which is certainly consistent with diverse in situ observations [e.g., Zilberman et al., 2011].

Shriver et al. [2014] analyzed the variability of internal tides in a global ocean model that resolved both tides and mesoscales. Their results do include the short-time-scale variability that arises from tidal propagation through a broadband mesoscale background, and the graphical summary of tidal variability in the model [Shriver et al., 2014, Figure 2b] appears to agree well with Figure 8.

Zaron [2015] used data from Jason-2 and CryoSat-2 crossovers to infer the properties of the nonstationary tide, averaged between $\pm 55^{\circ}$ latitude and restricted to water depths greater than $3000 \mathrm{~m}$, and found that the nonstationary tide accounted for approximately $30 \%$ of total tidal variance. When the $\sigma_{c}^{2}$ and $\sigma_{i}^{2}$ fields in Figures 5 and 8 are averaged over the same domain, it is found that the nonstationary tide accounts for $44 \%$ of the total. The technique used in Zaron [2015] relied on a frequency domain analysis combined with spatial averaging, while the present analysis has focussed on analysis in the wavenumber domain. The two approaches are essentially orthogonal, and there are a few reasons which might explain the different estimates for nonstationary versus total tidal variability. First, in Zaron [2015] it was impossible to separate the barotropic and baroclinic components of SSH variability, and the estimate for the stationary tidal variance there includes an unknown barotropic contribution from the smaller and more uncertain semidiurnal tides $\left(\mu_{2}, S_{2}, L_{2}\right.$, and $\left.N_{2}\right)$. The better exclusion of the barotropic component in the present analysis leads to smaller estimates of the stationary tide and a larger nonstationary fraction. In addition, the nonstationary component of the variance in that study was estimated by extrapolating a rather noisy time-lagged autocovariance towards zero, and it was restricted to lags shorter than 60 days. While the present approach is also uncertain with respect to the definition of the nonstationary tide, due to uncertainty in the model of the nontidal broadband spectrum, it is based on 23 years of altimeter data and includes nonstationarity at a much larger range of time scales. Based on these factors, it is hard to conclude that the difference between the results is significant.

\section{Summary}

An analysis of the wavenumber spectrum of $\mathrm{SSH}$ has been combined with a tidal analysis of the stationary tide in order to map the nonstationary mode-1 baroclinic semidiurnal tide over the oceans. In order to do this, it was assumed that the nonstationary tide is dominated by freely-propagating wave components with wavenumber given by the dispersion relation for linear internal waves. The stationary tide was estimated by ordinary harmonic analysis at each point along the satellite ground track, and the residual variance within a waveband surrounding the theoretically-predicted mode- 1 wavenumber was used to estimate the nonstationary tidal variance. In addition to the nonstationary tide, the residual variance contains contributions from broadband nontidal processes and noise, and the variance of these processes was estimated from a 


\section{QAGU Journal of Geophysical Research: Oceans}

simple model obtained by interpolating across the base of the spectral bump associated with the internal tide.

Both the stationary and nonstationary internal tides exhibit considerable spatial variability. In midlatitude western boundary currents, and in much of the Southern Ocean, there is no discernible bump in the spectrum associated with the mode- 1 internal tide. A bump in the spectrum is evident throughout much of the subtropics and equatorward, and in these regions, it is possible to make a plausible estimate for the nonstationary tide using the approach described. The nonstationary baroclinic tide is larger than the stationary component in almost all of the equatorial oceans, except for the eastern equatorial Atlantic.

The average ratio of nonstationary to total semidiurnal internal tide variance is $44 \%$, a value somewhat higher than has been estimated previously. The spatial pattern of the nonstationary tide appears to agree well with present-generation numerical models [Shriver et al., 2014].

Numerous studies have sought to rationalize open ocean tidal energetics as a balance between energy conversion from barotropic to baroclinic tides and the subsequent propagation and dissipation of the baroclinic tides [e.g., Buijsman et al., 2016]. The former is well-determined by altimetry data incorporated in data assimilative barotropic tide models [Egbert and Ray, 2001]. Energy transported and dissipated by the baroclinic tide is less well determined, and the present study provides an empirical estimate for the size of the nonstationary component of the mode- 1 semidiurnal tide which ought to be included in energetic budgets. The $44 \%$ fraction attributed to nonstationary tides is a measure of SSH variance, which is directly comparable to internal tide potential energy. Interpreted naively, existing altimeter-derived baroclinic tide energy flux estimates ought to be inflated by a factor of $1 /(1-0.44)$ to account for the energy flux of the nonstationary tide. This would be too crude, though, as the nonstationary fraction is apparently much smaller near the Hawaiian Ridge and other generation sites where the baroclinic energy flux has actually been estimated [Ray and Cartwright, 2001; Merrifield and Holloway, 2002; Zaron and Egbert, 2014]. More recent work around Luzon Strait, in the Philippine Sea and South China Sea, finds that the nonstationary tide is substantial [Kerry et al., 2016]. Based on Figure 8 , it may be predicted that the nonstationary component is significant or dominant in the tidal energetics of the Indian Ocean, the western equatorial Atlantic, and much of the equatorial Pacific.

Figure 8 is a useful guide for assessing where SSH observations from the upcoming SWOT mission will likely be contaminated by nonstationary tides. The variability shown in the figure is the square root of SSH variance, which corresponds to tidal amplitude a factor of $\sqrt{2}$ larger, so the peak-to-peak signal would be $2 \sqrt{2}$ times larger than that displayed. Over much of the oceans the SSH variability attributed to nonstationary internal tides is less than $0.5 \mathrm{~cm}$, or $1.4 \mathrm{~cm}$ peak-to-peak tidal contamination. However, the regions with larger nonstationary tides will have peak-to-peak signals in the $2-3 \mathrm{~cm}$ range. Interpretation of SWOT SSH observations in terms of geostrophic or balanced dynamics will likely require a nuanced approach that accounts for regional variability of tidal internal wave contamination and submesoscale dynamical balances.

\section{Acknowledgments}

Support for this project was provided by NASA award NNX09AF20G (Ocean Surface Topography Science Team). Satellite altimeter data used in this study were extracted from the RADAR Altimetry Database System (RADS; http://rads.tudelft.nl/rads/rads.shtml). The mesoscale sea-level anomaly maps were produced by Ssalto/Duacs and distributed by Aviso, with support from Cnes (http://www.aviso.altimetry. fr/duacs/). The comments of two reviewers helped improve this manuscript, and their contributions are appreciated.

\section{References}

Antony, C., and A. S. Unnikrishnan (2013), Observed characteristics of tide-surge interaction along the east coast of India and the head of Bay of Bengal, Estuar. Coast. Shelf Sci., 131, 6-11.

Arbic, B. K., A. J. Wallcraft, and E. J. Metzger (2010), Concurrent simulation of the eddying general circulation and tides in a global ocean model, Ocean Mod., 32, 175-187.

Barnett, T. P., and R. L. Bernstein (1975), Horizontal scales of midocean internal tides, J. Geophys. Res., 80(15), $1962-1964$.

Bennett, A. F. (2002), Inverse Modeling of the Ocean and Atmosphere, 234 pp., Cambridge Univ. Press, New York.

Boettger, D., R. Robertson, and L. Rainville (2015), Characterizing the semidiurnal internal tide of Tasmania using glider data, J. Geophys. Res. Oceans, 120, 3730-3746, doi:10.1002/2015JC010711.

Buijsman, M. C., J. K. Ansong, B. K. Arbic, J. G. Richman, J. F. Shriver, P. G. Timko, A. J. Wallcraft, C. B. Whalen, and Z. Zhao (2016), Impact of parameterized internal wave drag on the semidiurnal energy balance in a global ocean circulation model, J. Phys. Oceanogr., 46(5), 1399-1419.

Carrère, L., C. Le Provost, and F. Lyard (2004), On the statistical stability of the $\mathrm{M}_{2}$ barotropic and baroclinic tidal characteristics from alongtrack TOPEX/Poseidon satellite altimetry analysis, J. Geophys. Res., 109, C03033, doi:10.1029/2003JC001873.

Chiswell, S. M. (2002), Energy levels, phase, and amplitude modulation of the baroclinic tide off Hawaii, J. Phys. Oceanogr., 32, $2640-2651$.

Colosi, J. A., and W. Munk (2006), Tales of the venerable Honolulu tide gauge, J. Phys. Oceanogr., 36, 967-996.

Daniell, P. J. (1946), Discussion on the theoretical specification and sampling properties of autocorrelated time series, Suppl. J. Roy. Stat. Soc., 8, 88-90.

Dunphy, M., and K. G. Lamb (2014), Focusing and vertical mode scattering of the first mode internal tide by mesoscale eddy interaction, J. Geophys. Res. Oceans, 119, 523-536, doi:10.1002/2013JC009293.

Dushaw, B. (2015), An empirical model for mode-1 internal tides derived from satellite altimetry: Computing accurate tidal predictions at arbitrary points over the world oceans, Tech. Rep. APL-UW TM 1-15, Univ. of Wash. Appl. Phys. Lab., Seattle. 
Dushaw, B. D., P. F. Worcester, B. D. Cornuelle, B. M. Howe, and D. S. Luther (1995), Baroclinic and barotropic tides in the central North Pacific Ocean determined from long-range reciprocal acoustic transmissions, J. Phys. Oceanogr., 25, 631-647.

Egbert, G. D., and R. D. Ray (2000), Significant tidal dissipation in the deep ocean inferred from satellite altimeter data, Nature, 405, 775778.

Egbert, G. D., and R. D. Ray (2001), Estimates of $M_{2}$ tidal energy dissipation from TOPEX/POSEIDON altimeter data, J. Geophys. Res., $106(\mathrm{C} 10), 22,475-22,502$.

Egbert, G. D., S. Y. Erofeeva, and E. D. Zaron (2012), Mapping $M_{2}$ internal tides using a data-assimilative reduced gravity model, AGU Program Book, Ocean Sci. Meet., Abstract B2112.

Fu, L. (1983), On the wave number spectrum of oceanic mesoscale variability observed by the SEASAT altimeter, J. Geophys. Res., 88(C7), 4331-4341.

Fu, L., and R. Ferrari (2008), Observing oceanic submesoscale processes from space, EOS, 89(48), 488-489.

Garrett, C., and E. Kunze (2007), Internal tide generation in the deep ocean, Annu. Rev. Fluid Mech., 39, 57-87, doi:10.1146/ annurev.fluid.39.050905.110227.

Glazman, R. E., and B. Cheng (1999), Altimeter observations of baroclinic oceanic inertia-gravity wave turbulence, Proc. R. Soc. Lond. A, 455, 91-123.

Goff, J. A. (2009), Statistical characterization of Geosat altimetry noise: Dependence on environmental parameters, Geochem. Geophys. Geosys., 10, Q08007, doi:10.1029/2009GC002569.

Gourdeau, L. (1998), Internal tides observed at $2^{\circ}$ S- $156^{\circ} \mathrm{E}$ by in situ and TOPEX/POSEIDON data during the Coupled Ocean-Atmosphere Response Experiment (COARE), J. Geophys. Res., 103(C6), 12,629-12,638.

Hendershott, M. C. (1981), Long waves and ocean tides, in Evolution of Physical Oceanography, edited by B. A. Warren and C. Wunsch, pp. 293-341, MIT Press, Cambridge, Mass.

Kang, S. K., J. Chung, S. Lee, and K. Yum (1995), Seasonal variability of the $M_{2}$ tide in the seas adjacent to Korea, Contin. Shelf Res., 15(9), $1087-1113$.

Kelly, S. M., N. L. Jones, G. N. Ivey, and R. J. Lowe (2015), Internal tide spectroscopy and prediction in the timor sea, J. Phys. Oceanogr., 45, 64-83, doi:10.1175/JPO-D-14-0007.1.

Kerry, C. G., B. S. Powell, and G. S. Carter (2016), Quantifying the incoherent $M_{2}$ internal tide in the Philippine Sea, J. Phys. Oceanogr., 46(8), 2457-2481.

Kitamura, Y., and Y. Matsuda (2006), The $k_{h}^{-3}$ and $k_{h}^{-5 / 3}$ energy spectra in stratified turbulence, Geophys. Res. Lett., 33, L05809, doi:10.1029/ 2005 GL024996.

Konyaev, K. V., K. D. Sabinin, and A. N. Serebryany (1995), Large-amplitude internal waves at the Mascarene Ridge in the Indian Ocean, Deep Sea Res. I, 42(11), 2075-2091.

LeProvost, C. (2001), Ocean tides, in Satellite Altimetry and Earth Sciences, Int. Geophys. Ser., vol. 69, edited by L.-L. Fu and A. Cazenave, pp. 267-303, Academic, San Francisco, Calif.

LeTraon, P., M. C. Rouquet, and C. Boissier (1990), Spatial scales of mesoscale variability in the North Atlantic as deduced from Geosat data, J. Geophys. Res., 95(C11), 20,267-20,285.

LeTraon, P. Y., P. Klein, B. L. Hua, and G. Dibarboure (2008), Do altimeter spectra agree with the interior or surface quasigeostrophic theory? J. Phys. Oceanogr., 38, 1137-1142.

Magaard, L., and W. D. McKee (1973), Semidiurnal tidal currents at site D, Deep Sea Res., 20(11), 997-1009.

Merrifield, M. A., and P. E. Holloway (2002), Model estimates of $M_{2}$ internal tide energetics at the Hawaiian Ridge, J. Geophys. Res., 107(C8), doi:10.1029/2001JC000996.

Mirouze, I., and A. Weaver (2010), Representation of the correlation functions in variational data assimilation using an implicit diffusion operator, Quart. J. Royal Met. Soc., 136, 1421.

Morozov, E. G., and V. I. Vlasenko (1996), Extreme tidal internal waves near the Mascarene Ridge, J. Mar. Sys., 9(3), 203-210.

Muller, M., J. Cherniawsky, M. G. Foreman, and J.-S. von Storch (2014), Seasonal variation of the M2 tide, Ocean Dyn., 64(2), 159-177.

Murty, T. S., and R. F. Henry (1983), Tides in the bay of bengal, J. Geophys. Res., 88(C10), 6069-6076.

Ponte, A. L., and P. Klein (2015), Incoherent signature of internal tides on sea level in idealized numerical simulations, Geophys. Res. Lett., 42, 1520-1526, doi:10.1002/2014GL062583.

Ray, R. D. (1998), Spectral analysis of highly aliased sea-level signals, J. Geophys. Res., 103(C11), 24,991-25,003.

Ray, R. D., and D. A. Byrne (2010), Bottom pressure tides along a line in the southeast Atlantic Ocean and comparisons with satellite altimetry, Ocean Dyn., 60, 1167-1176.

Ray, R. D., and D. E. Cartwright (2001), Estimates of internal tide energy fluxes from TOPEX/POSEIDON altimetry: Central North Pacific, Geophys. Res. Lett., 28(7), 1259-1262.

Ray, R. D., and G. T. Mitchum (1996), Surface manifestation of internal tides generated near Hawaii, Geophys. Res. Lett., $23(16), 2101-2104$.

Ray, R. D., and E. D. Zaron (2011), Non-stationary internal tides observed with satellite altimetry, Geophys. Res. Lett., 38, L17609, doi:10.1029/ $2011 \mathrm{GL} 048617$.

Ray, R. D., and E. D. Zaron (2016), $M_{2}$ internal tides and their observed wavenumber spectra from satellite altimetry, J. Phys. Oceanogr., 46 , $3-22$.

Shriver, J. F., J. G. Richman, and B. K. Arbic (2014), How stationary are the internal tides in a high-resolution global ocean circulation model?, J. Geophys. Res. Oceans, 119, 2769-2787, doi:10.1002/2013JC009423.

Sindhu, B., and A. S. Unnikrishnan (2013), Characteristics of tides in the Bay of Bengal, Marine Geodesy, 36(4), 377-407.

Stammer, D. (1997), Global characteristics of ocean variability estimated from regional TOPEX/POSEIDON altimeter measurements, J. Phys. Oceanogr., 27, 1743-1769.

Weisberg, R. H., D. Halpern, T. Y. Tang, and S. M. Hwang (1987), M2 tidal currents in the Eastern Equatorial Pacific Ocean, J. Geophys. Res., 92(C4), 3821-3826.

Wolanski, E., and G. L. Pickard (1983), Upwelling by internal tides and Kelvin waves at the continental shelf break on the Great Barrier Reef, Aust. J. Mar. Freshw. Res., 34, 65-80.

$\mathrm{Xu}, \mathrm{Y}$., and L. Fu (2011), Global variability of the wavenumber spectrum of oceanic mesoscale turbulence, J. Phys. Oceanogr., 41, 802-809.

Yale, M. M., D. T. Sandwell, and W. H. Smith (1995), Comparison of along-track resolution of stacked Geosat, ERS 1, and TOPEX satellite altimeters, J. Geophys. Res., 100(B8), 15,117-15,127.

Zaron, E. D. (2014), Combined exact-repeat and geodetic mission altimetry for high-resolution empirical tide mapping, AGU Program Book, AGU Fall Meet., Abstract OS41B-1194.

Zaron, E. D. (2015), Properties of non-stationary tides inferred from dual-satellite crossovers, J. Phys. Oceanogr., 45(9), $2239-2246$. 
Zaron, E. D., and G. D. Egbert (2014), Time-variable refraction of the internal tide at the Hawaiian Ridge, J. Phys. Oceanogr., $44(2), 538-557$. Zaron, E. D., and D. A. Jay (2014), An analysis of secular change in tides at open-ocean sites in the Pacific, J. Phys. Oceanogr., 44(7), 17041726.

Zhao, Z., M. H. Alford, J. B. Girton, L. Rainville, and H. L. Simmons (2016), Global observations of open-ocean mode-1 M2 internal tides, J. Phys. Oceanogr., 46, 1657-1684.

Zhou, X.-H., D.-P. Wang, and D. Chen (2015), Validating satellite altimeter measurements of internal tides with long-term TAO/TRITON buoy observations at $2^{\circ} \mathrm{S}-156^{\circ} \mathrm{E}$, Geophys. Res. Lett., 42, 4040-4046, doi:10.1002/2015GL063669.

Zilberman, N. V., M. A. Merrifield, G. S. Carter, D. S. Luther, M. D. Levine, and T. J. Boyd (2011), Incoherent nature of $M_{2}$ internal tides at the Hawaiian Ridge, J. Phys. Oceanogr., 41(11), 3021-2036. 